\title{
Concentrations and Size Distributions of Particle Lung-deposited Surface Area (LDSA) in an Underground Mine
}

\author{
Laura Salo ${ }^{1}$, Topi Rönkkö ${ }^{1}$, Sanna Saarikoski², Kimmo Teinilä², Joel Kuula², \\ Jenni Alanen ${ }^{1}$, Anssi Arffman ${ }^{1+}$, Hilkka Timonen ${ }^{2}$, Jorma Keskinen ${ }^{1}$ \\ ${ }^{1}$ Aerosol Physics Laboratory, Physics Unit, Tampere University, Tampere 33720, Finland \\ ${ }^{2}$ Atmospheric Composition Research, Finnish Meteorological Institute, Helsinki 00560, Finland
}

\section{ABSTRACT}

Ultrafine particles produced by diesel-powered vehicles in underground mines are largely unaccounted for in mass-based air quality metrics. The Lung Deposited Surface Area concentration (LDSA) is an alternative to describe the harmfulness of particles. We aim to study concentrations and size distributions of LDSA at various locations in an underground mine as well as to evaluate the applicability of sensor-type measurement of LDSA. This study was conducted in an underground mine in Kemi, Finland, in 2017. Our main instrument was an electrical low-pressure impactor $(\mathrm{ELPI}+)$ inside a mobile laboratory. Additionally, five diffusion-charging based sensors were tested. The environment was challenging for the sensors as the particle size distribution was often outside the optimum range $(20-300 \mathrm{~nm})$ and dust accumulated inside the instruments. Despite this, the correlations with the ELPI+ were decent ( $\mathrm{R}^{2}$ from 0.53 to 0.59 ). With the ELPI+ we determined that the maintenance area had the lowest mean LDSA concentration $\left(79 \pm 38 \mu \mathrm{m}^{2}\right.$ $\mathrm{cm}^{-3}$ ) of the measured locations. At the other locations, concentrations ranged from 137 to $405 \mu \mathrm{m}^{2} \mathrm{~cm}^{-3}$. The mode particle size for the LDSA distribution was around $100 \mathrm{~nm}$ at most locations, with the blasting site as a notable exception (mode size closer to $700 \mathrm{~nm}$ ). Diffusioncharging based sensors - perhaps aided by optical sensors-are potential solutions for long-term monitoring of LDSA if dust accumulation is taken care of. Our research indicates worker exposure could be reduced with the implementation of a sensor network to show which locations need either protective gear or increased ventilation.

Received: December 11, 2020

Revised: April 13, 2021

Accepted: April 20, 2021

${ }^{*}$ Corresponding Author:

laura.salo@tuni.fi

† Present address: Dekati Ltd., Kangasala 36240, Finland

\section{Publisher:}

Taiwan Association for Aerosol Research

ISSN: $1680-8584$ print

ISSN: 2071-1409 online

(c) Copyright: The Author(s). This is an open access article distributed under the terms of the Creative Commons Attribution License (CC BY 4.0), which permits unrestricted use, distribution, and reproduction in any medium, provided the original author and source are cited.

\section{INTRODUCTION}

Particulate matter (PM) in the air is known to be harmful for human health (Lelieveld et al., 2015; Burnett et al., 2018), mostly due to the ability of particles to penetrate and deposit into the human lungs (Pope, 2000; Pope and Dockery, 2006). This lung-deposition, as well as the deposition of particles in other parts of the human respiratory tract, is strongly dependent on the size distribution of particles. Especially ultrafine particles (particle diameter smaller than $100 \mathrm{~nm}$ ) and to some extent larger fine particles (particle diameter smaller than $2.5 \mu \mathrm{m}$ ) can reach the most vulnerable alveolar areas of human lungs and deposit there (Oberdörster, 2001). These particles can consist of compounds that are toxic for the human body or they can carry the toxic components on their surfaces (Goulaouic et al., 2008). In addition to acute symptoms, the particulate matter of inhaled air has been observed to cause cardiovascular diseases, lung cancer and brain diseases (Grahame et al., 2014).

Historically, mine work has been a notably hazardous occupation, but even modern-day mines often struggle with air quality concerns. Underground mines are especially challenging environments, and efficient mechanical ventilation is necessary for keeping the air clear of polluting gases and 
particles. The particulate matter originates from different sources: exhaust of mine vehicles, surfaces of mine galleries, and from the different processes related to mining work (Saarikoski et al., 2019; Afshar-Mohajer et al., 2020). The particles from different sources have varying chemical and physical characteristics and the total mixture and concentration of particles can therefore vary significantly, both temporally and spatially (Saarikoski et al., 2019), making monitoring and air quality control a challenge. Ventilation of an underground mine is an energy-intensive process, so to limit costs it is preferential to use increased ventilation only at times and places where workers are at risk of exposure. To protect against particle inhalation, workers may also use personal protection (masks), or stay inside vehicles equipped with HEPA-filters (High-efficiency particulate air filter).

In outdoor air, coarse (PM10, sub $10 \mu \mathrm{m})$ and fine (PM2.5, sub $2.5 \mu \mathrm{m})$ particles are closely monitored and efforts are put into keeping mass concentrations low. The World Health Organization gives guidelines for yearly averages of $\mathrm{PM}_{2.5}\left(10 \mu \mathrm{g} \mathrm{m}^{-3}\right)$ and $\mathrm{PM}_{10}\left(20 \mu \mathrm{g} \mathrm{m}^{-3}\right)$. Occupational exposure limits are much higher and vary from country to country. Some countries set limits on inhalable dust $\left(\mathrm{PM}_{100}\right)$, while others limit respirable dust $\left(\sim \mathrm{PM}_{4}\right)$ or thoracic dust (another name for $\mathrm{PM}_{10}$ ). The Finnish Institute of Occupational Health (FIOH) recommends limits of $2000 \mu \mathrm{g} \mathrm{m}^{-3}$ for inhalable dust and $500 \mu \mathrm{g} \mathrm{m}^{-3}$ for respirable dust (Hyytinen et al., 2016). In addition, diesel particulate matter (DPM) is often monitored, usually measured indirectly through a surrogate, such as elemental carbon (Noll et al., 2007; Pronk et al., 2009). For DPM limits, FIOH uses Switzerland's officials' suggested value of $100 \mu \mathrm{g} \mathrm{m}^{-3}$ for elemental carbon (Taxell et al., 2015). Most recent aerosol studies related to underground mining focus on DPM, as there is evidence of health effects related to it (Chang and Xu, 2017; Barrett et al., 2019). The problem with these existing massbased exposure limits is that they do not adequately account for ultrafine particles (sub $100 \mathrm{~nm}$ ), which are able to penetrate deep into human airways and deposit into lung alveoli (Braakhuis et al., 2014). This is especially worrisome, since the majority of particle emissions (measured by number) from diesel engines fall into the ultrafine category (Karjalainen et al., 2019; Pirjola et al., 2019).

One metric better suited for ultrafine particle measurement is the Lung Deposited Surface Area (LDSA) concentration of particles. It has been introduced to describe the harmfulness of particulate pollutants of inhaled air. LDSA combines the idea that toxic compounds lie especially on the surfaces of particles, with deposition efficiency of particles into the alveolar area of the human respiratory system. The LDSA of 20-300 nm particles can be easily monitored by sensor type devices (Kuuluvainen et al., 2018; Kuula et al., 2019) which has increased its use in air quality monitoring applications, especially related to urban ambient air. The sensors are small, stand-alone units, allowing them to be used in sensor networks for overall air quality monitoring or for personal exposure monitoring. The first instrument designed for LDSA measurement was presented by Fissan et al. (2007), and since then many more designs have become available. In the original LDSA instrument, the user could choose to measure the deposition in a certain lung-region, but recent research has focused on the alveolar region, as it has been assumed to have the highest health-impact.

LDSA concentrations, size distribution and height profiles have been measured in ambient conditions in different urban environments (Kuuluvainen et al., 2016; Kuula et al., 2020; Tran et al., 2020). In urban ambient air studies, the LDSA concentrations have been observed to be linked with emissions from combustion sources, such as engines and residential wood burning. Studies conducted in working environments and indoor conditions have measured LDSA e.g., to characterize LDSA exposure in printing centers (Setyawati et al., 2020) or to study influence of air cleaner devices to LDSA in offices (Küpper et al., 2019). In ambient air the LDSA concentrations typically vary from $\sim 10-50 \mu \mathrm{m}^{2} \mathrm{~cm}^{-3}$ measured at clean background areas (Kuula et al., 2020), to values up to $\sim 100-150 \mu \mathrm{m}^{2} \mathrm{~cm}^{-3}$ typically observed near PM sources such as roads (Leavey et al., 2017; Cheristanidis et al., 2020). LDSA concentrations related to mining operations have recently been studied using real time instruments in the context of open taconite mining operations. Huynh et al. (2018) studied ambient fine particle concentration in six taconite mines, using several particle concentration metrics, including LDSA. In their study, LDSA concentrations ranged from 50 to $300 \mu \mathrm{m}^{2} \mathrm{~cm}^{-3}$ depending on the processing area. Afshar-Mohajer et al. (2020) studied the variability of aerosol concentrations in different processing areas of a taconite mine using different metrics, including LDSA, which ranged from 85 to $200 \mu \mathrm{m}^{2} \mathrm{~cm}^{-3}$. Within these studies, the highest readings were found in the pelletizing area. To the best of our knowledge, LDSA concentrations of underground mines have not been reported before. 
In this study, we measured total LDSA along with the LDSA size distribution of particles up to $10 \mu \mathrm{m}$. The measurements were conducted in an underground mine in Kemi, Finland, in 2017. The aim of this article is to report the concentrations of LDSA in various locations in the mine and evaluate the applicability of LDSA as a measurement metric and the applicability of sensor-type measurements of LDSA in a mine environment.

\section{METHODS}

The total LDSA and LDSA particle size distributions were measured in an underground chrome mine located in Kemi, Finland, and operated by Outokumpu. The mine has been in operation since 1968 , and the underground operations began in 2003. In 2016, the mine employed approximately 200 people through Outokumpu and an additional 300 people through permanent contractors, and in total, 3 million tons of rock was mined within the year (https://www.kaivosvastuu.fi/yrity skortti/outokumpu-chrome-oy/). The measurement campaign took place from March $21^{\text {st }}$ to March $30^{\text {th }}$ in 2017. Two sensors were left to monitor the mine air for an additional 12 days, until April $11^{\text {th }}$.

Five measurement sites were chosen for this study, each to represent an aerosol source or a location of personnel exposure (or both). Three sites-the dumping area, crushing station and maintenance area-each had workers operating in the area, although in the dumping area most workers were inside vehicles. The maintenance area also had vehicle traffic, and many people were also walking in the area, as offices and the cafeteria were located on this level. The two remaining sites were the blasting area and conveyor belt. The blasting area did not have workers during the blasting for safety reasons, but trucks arrived shortly afterwards to transport rocks. The conveyor belt location did not have much human activity during our measurements, although the belt itself was in operation. We expected vehicle emissions to be present in all locations, but especially in the dumping area and in the blasting area (after the blasting, which were scheduled to be at 14:00 and 22:00), where heavy-duty traffic was frequent. The maintenance area was frequented by passenger vehicles, taking people to the offices and cafeteria, so some traffic exhaust was expected to originate from there as well. We expected to see coarser particles at the crushing station as well as the blast site. The measurement locations along with the mobile laboratory setup are described in more detail by Saarikoski et al. (2019), where other aspects (particle mass, number, and chemical composition) of this measurement campaign are reported.

Measurements were conducted primarily using ELPI+ (Electrical Low-Pressure Impactor, Dekati Ltd.) but, in addition, the applicability and performance of five smaller, sensor-type instruments was tested in the mine environment.

ELPI+ is a 14-stage low-pressure cascade impactor. Unlike in traditional impactors, the particles are measured electrically in real time (Keskinen et al., 1992). For the particles to be detected, they are first charged with positive ions from a diffusion charger. The raw data from the instrument is the current measured from each of the 14 stages. The lowest stage is a filter, which collects essentially all particles, but due to weakened charging of very small particles, the lowest detectable size is $6 \mathrm{~nm}$. Before the highest stage, there is an impactor to remove particles over $10 \mu \mathrm{m}$ in aerodynamic size. When handling the data, the currents were first corrected using zero measurement data (current measured when a HEPA filter was placed at the inlet) and then adjusted to account for secondary collection by diffusion (Järvinen et al., 2014). The LDSA distribution was then calculated from the current distribution, using the method described by Lepistö et al. (2020). Total LDSA was calculated for different size ranges, based on the impactor cut-off sizes. In this article we have rounded the actual cut-off sizes to nearest round values, true cut-offs can be found in Table S1.

The chemical composition of submicron $(<1 \mu \mathrm{m})$ particles was determined by a Soot Particle Aerosol Mass Spectrometer (Aerodyne Research Inc.). The SP-AMS was equipped with both laser and tungsten vaporizers, and therefore, it was able to measure both non-refractory material (organics, sulfate, nitrate, ammonium and chloride), and refractory material (i.e., the refractory BC and metals) in particles. The details of the SP-AMS analysis can be found in Saarikoski et al. (2019). Additionally, the black carbon concentrations were measured with a dualspot Aethalometer (AE33; Magee Scientific). 
The five electrical particle sensors included in this study were two Partectors (Naneos), one DiSCmini (Testo) and two AQ Indoors (Pegasor). The sensors employ a diffusion charger to charge incoming particles and the electrical current generated by the particles is measured. The raw current is transformed into LDSA using an internal calibration factor. The calibration factor relies on the linear relationship between diffusion charging and LDSA, but this linear relationship is only true for a rather small size range of approximately $20-300 \mathrm{~nm}$. If a sensor is calibrated with 100 $\mathrm{nm}$ particles, as is the case with the Partector, then the LDSA of $300 \mathrm{~nm}$ particles will be overestimated, while the LDSA of $50 \mathrm{~nm}$ particles is under-estimated (Fierz et al., 2014). The three different sensor types employed in this study all measure alveolar deposition.

While each of the sensors uses the same basic principle for LDSA measurement, there are some notable differences in the measurement techniques. The Partector uses pulsed charging, and it measures the induced current created by the changing charge (Fierz et al., 2014). The benefit of this method is that the particles do not need to be collected. The DiSCmini has two-stage collection, which allows for it to estimate the mean size of the particle population. The first stage is a diffusion collector, collecting only the smallest particles, and the second stage is a filter, collecting what is left over after the first stage. The AQ Indoor employs a particle trap with a cycling voltage to remove some of the particle population, also allowing for an estimation of the particle size. The larger the voltage, the larger the particles which can be removed. To ensure coarse particles and dirt do not get inside the sensors, the Partector uses a wire mesh at the inlet, the DiSCmini has an impactor which can be inserted at the inlet, and $A Q$ Indoor has a cyclone.

The ELPI+ was located inside a mobile measurement laboratory along with various other air quality instruments. The sensors were located initially in the Maintenance area of the mine and connected to each other with Tygon tubing, to make sure they sampled the same air for the duration of a sensor comparison. Later, the AQ Indoor sensors were moved to different locations in the mine ( $A Q$ Indoor $A$ to the dumping area and $A Q$ Indoor $B$ to the crushing station), for the sensor network type measurement. The Partector and DiSCmini instruments began reporting faults after just a few days of measurements, due to over-loading, and were not employed further.

\section{RESULTS}

Fig. 1 shows the time series of total LDSA concentration, based on the measurements using ELPI+. Color bars in the figure indicate measurement locations and time periods analyzed, these are the same times and locations as in the study by Saarikoski et al. (2019). In general, Fig. 1 shows that the LDSA concentration had a large spatial and temporal variation in the air of studied underground mine. This variation can be seen both between the locations and within one location as a function of time. For instance, in the blasting area, the total LDSA concentration varied from values lower than $100 \mu \mathrm{m}^{2} \mathrm{~cm}^{-3}$ to values larger than $700 \mu \mathrm{m}^{2} \mathrm{~cm}^{-3}$, and similar variation can be seen in crushing station. In the maintenance area the LDSA concentration remained relatively low,

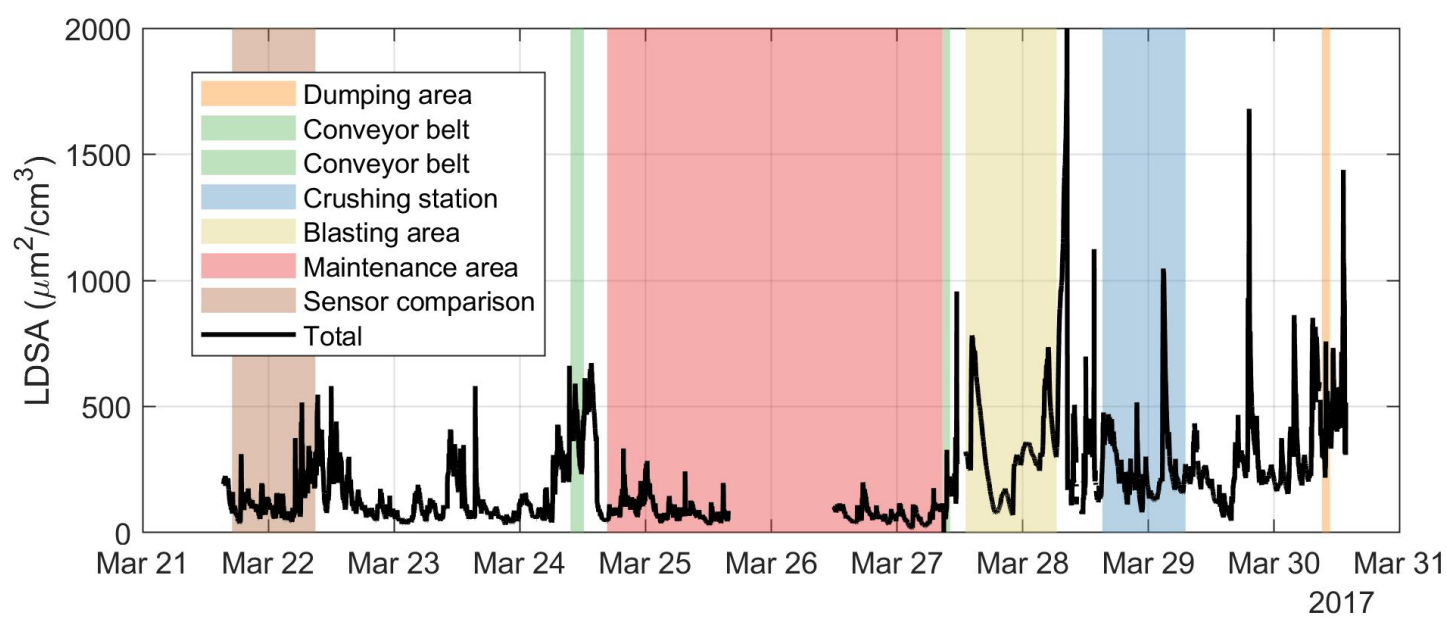

Fig. 1. Timeseries of total LDSA concentration measured with ELPI+, and measurement locations shown with color bars. 
mostly under $200 \mu \mathrm{m}^{2} \mathrm{~cm}^{-3}$. In general, rapid changes in LDSA concentrations indicate that local sources affect the concentrations. However, measurements conducted simultaneously in two different locations (dumping area and crushing site, Fig. S1) indicate that emissions also spread between locations. Sensors were also used to measure LDSA inside the canteen and offices located at the maintenance level, separated by doors. Both locations showed essentially zero LDSA concentrations.

Fig. 2 shows the time series of particle LDSA size distributions for each measurement location. The figure shows that particle sizes from $10 \mathrm{~nm}$ to $6 \mu \mathrm{m}$ contribute to the LDSA in an underground mine. However, the relative contribution of different size ranges varies among locations. The highest contributions from largest particles, i.e., from particles larger than $200 \mathrm{~nm}$ in diameter, were observed in the blasting area and were directly linked with blasting events. However, occasional short periods of high LDSA from large particles were also observed at the crushing station and in the maintenance area, where the sensor comparison was made. While at the crushing station the high LDSA concentration was likely from a local source, in the maintenance area it was most likely caused by blasting originated large particles transported from a distant blasting event.

Fig. 3 shows the time-averaged particle LDSA size distributions. In the figure, each line corresponds to one of the color plots in Fig. 2. Most locations had the largest particle mode around 50-200 nm, the Blasting area being the main exception, with a mode size around $500 \mathrm{~nm}$. Several locations had two particle modes. Looking back at Fig. 2, at the blasting area and the crushing station these
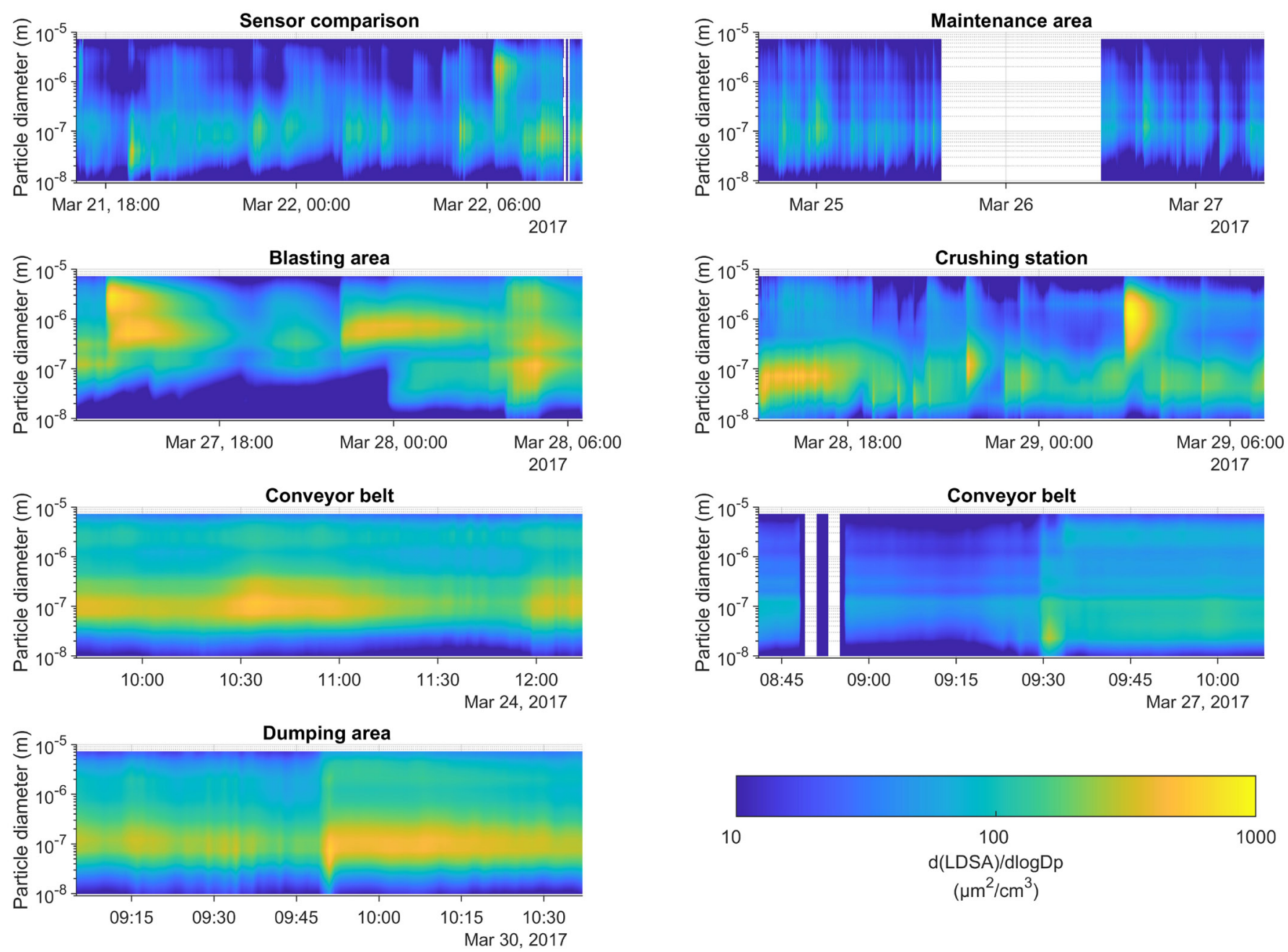

Fig. 2. Location-specific LDSA distribution timeseries measured with ELPI+. The sensor comparison was conducted in the Maintenance area. Note that the Conveyor belt and Dumping area measurements were much shorter than others, due to difficulties with the power supply. 


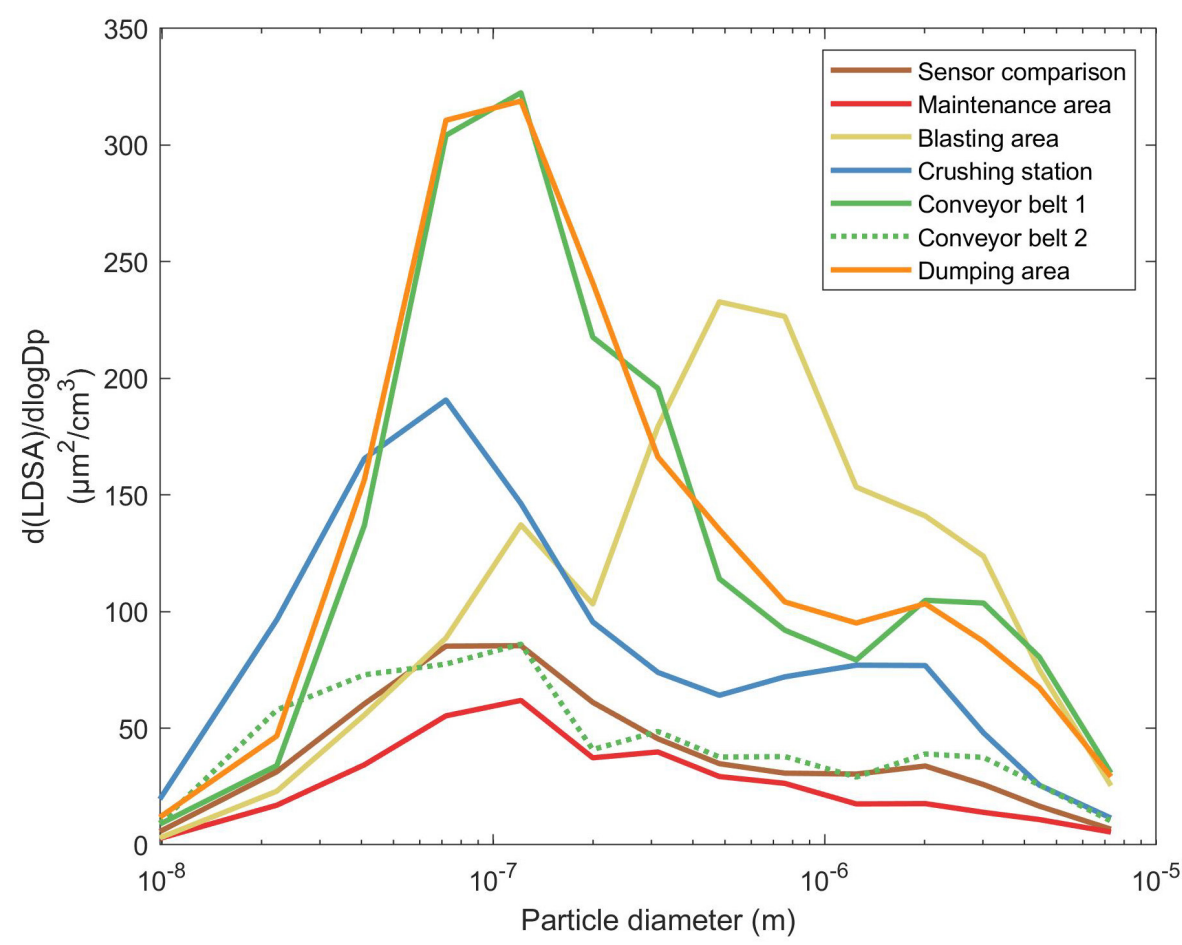

Fig. 3. Mean LDSA size distribution from each location.

different modes occur independently, meaning they must be from different sources. In contrast, at the dumping area and conveyor belt, both modes appear at the same time. The particles are either from the same source, or from different sources which have activity at the same time. From Fig. 3 it may seem as though the conveyor belt and dumping area had less activity (plots are smooth); however, the smooth appearance is due to the shorter time periods measured. The dumping area was also measured with a sensor for a longer duration (Fig. S1), which shows dramatic changes in the total LDSA.

Fig. S2 shows the chemical composition of particles by mass fraction, plotted against particle size. As the data is by mass, it is difficult to directly compare with the LDSA size distributions in Figs. 2 and 3. However, the particles consisted mostly of organics, with black carbon (soot) being the second most common substance. The blasting area had a large amount of sulphate as well. It should be noted that the SP-AMS only detects particles up to $1 \mu \mathrm{m}$ in diameter, and it requires that the detected particles either vaporize at $600^{\circ} \mathrm{C}$ or absorb light at a wavelength of $1064 \mathrm{~nm}$, which is why it did not detect mineral dust. In-depth discussion on the aerosol chemical composition can be found in Saarikoski et al. (2019).

Table 1 contains a summary of the numerical results for LDSA for each measurement location (columns) and separated into particle size ranges (rows). The size ranges have been selected to relate to the conventions in mass concentration measurement $\left(\mathrm{PM}_{10}, \mathrm{PM}_{2.5}, \mathrm{PM}_{1}, \mathrm{PM}_{0.1}\right)$; additionally, diffusion-charging based sensors are often calibrated for sizes between $30-300 \mathrm{~nm}$. The table shows that a large portion of particles (34-70\%) is measured incorrectly with these sensors, due to the particles being larger than the size range that the sensors are calibrated for. On the other hand, less than $13 \%$ of LDSA is contributed from particles over $2.5 \mu \mathrm{m}$.

Fig. 4 shows a time series (top panel) of the sensor comparison performed the beginning of the measurement campaign (see Fig. 1). Five different diffusion-charging sensors were used, and the 5-minute averaged values were compared to ELPI+. The lower plot shows the correlation between $\mathrm{ELPI}+$ and each sensor, along with fitted lines. The best correlations were with $A Q$ Indoor $\left(A\right.$ and $\left.B, R^{2}=0.59\right)$. Some of the discrepancy between ELPI+ and the sensors is probably due to the slightly different measurement locations (the ELPI+ measurement point was approximately 5 meters away from the sensors). The largest discrepancy between sensors and ELPI+ was at the end of the sensor comparison, where all sensors overestimated the LDSA concentration. The overestimation did not persist after the sensors were moved to new locations (Fig. S4, Fig. S5). 
Correlations between each of the similar sensor pairs (Partector A \& B, AQ Indoor A \& B) are in Fig. S6. The $A Q$ Indoor sensors were remarkably well-correlated, with a correlation factor of $R^{2}=$ 1.00 .

Table 1. Mean and standard deviation of LDSA $\left(\mu \mathrm{m}^{2} \mathrm{~cm}^{-3}\right)$ for each measurement location (measured with ELPI+) divided into particle size bins. The percentage represents the fraction of LDSA attributable to particles smaller than the specified size.

\begin{tabular}{|c|c|c|c|c|c|c|c|}
\hline \multicolumn{8}{|c|}{ LDSA mean \pm standard deviation $\left(\mu \mathrm{m}^{2} \mathrm{~cm}^{-3}\right)$} \\
\hline & $\begin{array}{l}\text { Sensor } \\
\text { comparison }\end{array}$ & $\begin{array}{l}\text { Maintenance } \\
\text { area }\end{array}$ & $\begin{array}{l}\text { Blasting } \\
\text { area }\end{array}$ & $\begin{array}{l}\text { Crushing } \\
\text { station }\end{array}$ & $\begin{array}{l}\text { Conveyor } \\
\text { belt } 1\end{array}$ & $\begin{array}{l}\text { Conveyor } \\
\text { belt } 2\end{array}$ & $\begin{array}{l}\text { Dumping } \\
\text { area }\end{array}$ \\
\hline \multirow{2}{*}{ Total (Sub $10 \mu \mathrm{m}$ ) } & $120 \pm 66$ & $79 \pm 38$ & $323 \pm 175$ & $270 \pm 157$ & $389 \pm 89$ & $137 \pm 68$ & $405 \pm 107$ \\
\hline & $100 \%$ & $100 \%$ & $100 \%$ & $100 \%$ & $100 \%$ & $100 \%$ & $100 \%$ \\
\hline \multirow[t]{2}{*}{ Sub $2.5 \mu \mathrm{m}$} & $112 \pm 59$ & $74 \pm 36$ & $282 \pm 139$ & $246 \pm 138$ & $349 \pm 84$ & $124 \pm 62$ & $370 \pm 93$ \\
\hline & $94 \%$ & $94 \%$ & $87 \%$ & $91 \%$ & $90 \%$ & $91 \%$ & $91 \%$ \\
\hline \multirow[t]{2}{*}{ Sub $1 \mu \mathrm{m}$} & $99 \pm 49$ & $67 \pm 33$ & $220 \pm 107$ & $214 \pm 93$ & $312 \pm 80$ & $110 \pm 55$ & $329 \pm 85$ \\
\hline & $83 \%$ & $84 \%$ & $68 \%$ & $80 \%$ & $80 \%$ & $80 \%$ & $81 \%$ \\
\hline \multirow[t]{2}{*}{ Sub $300 \mathrm{~nm}$} & $79 \pm 42$ & $49 \pm 25$ & $97 \pm 77$ & $175 \pm 74$ & $237 \pm 64$ & $86 \pm 46$ & $253 \pm 71$ \\
\hline & $66 \%$ & $62 \%$ & $30 \%$ & $65 \%$ & $61 \%$ & $63 \%$ & $62 \%$ \\
\hline \multirow[t]{2}{*}{ Sub 100 nm } & $47 \pm 30$ & $28 \pm 14$ & $44 \pm 46$ & $122 \pm 56$ & $120 \pm 33$ & $58 \pm 37$ & $132 \pm 43$ \\
\hline & $39 \%$ & $35 \%$ & $14 \%$ & $45 \%$ & $31 \%$ & $42 \%$ & $32 \%$ \\
\hline \multirow[t]{2}{*}{ Sub 30 nm } & $11 \pm 10$ & $6 \pm 4$ & $8 \pm 11$ & $35 \pm 14$ & $13 \pm 4$ & $20 \pm 19$ & $18 \pm 9$ \\
\hline & $9 \%$ & $7 \%$ & $2 \%$ & $13 \%$ & $3 \%$ & $15 \%$ & $4 \%$ \\
\hline
\end{tabular}
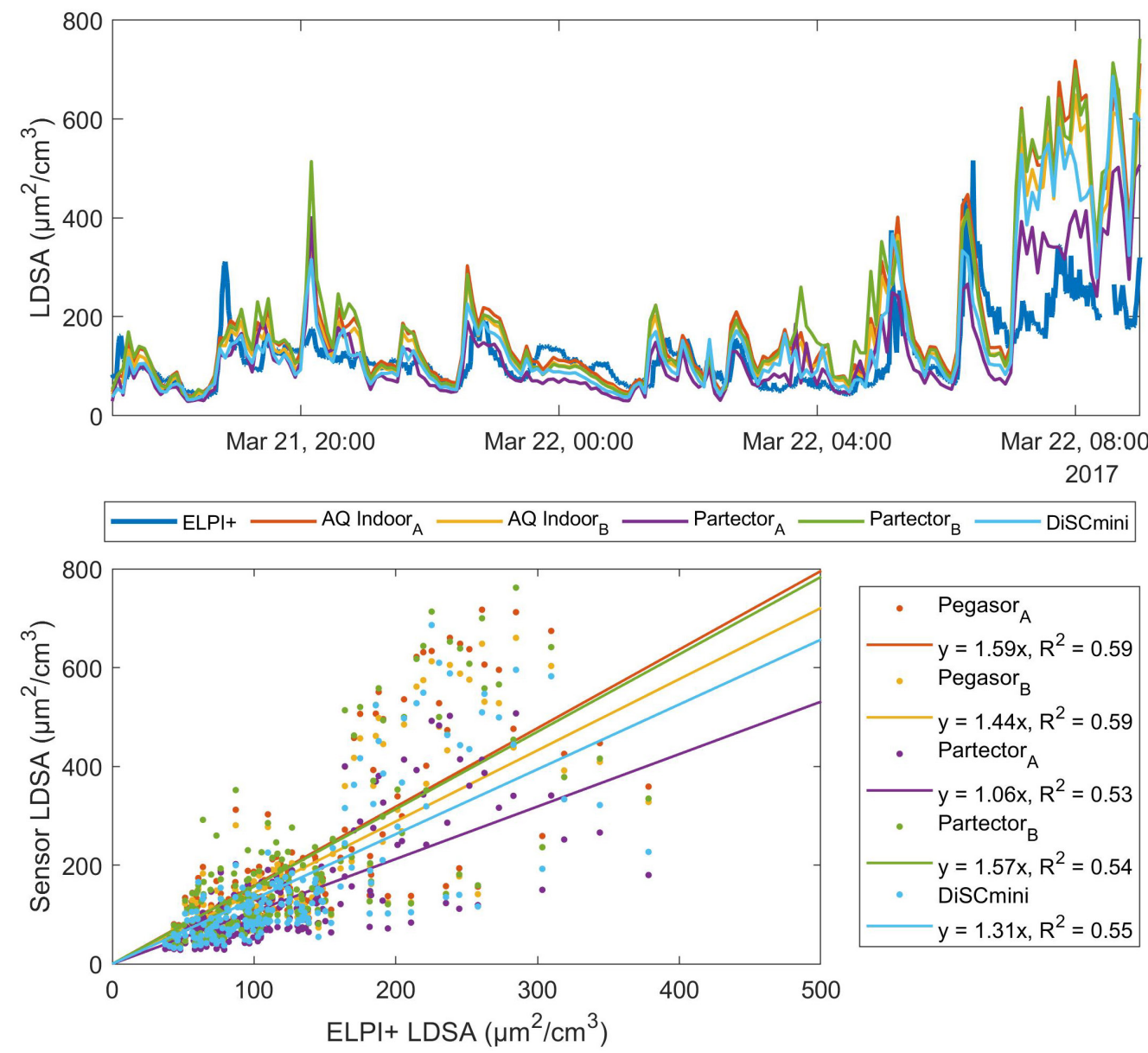

Fig. 4. Time series of electrical sensors and ELPI+ measuring LDSA concentration and related correlation plot. The sensors were all located on a table in the mine, whereas ELPI+ was measuring about $5 \mathrm{~m}$ away, inside the mobile laboratory. 
During the measurements, the Partectors and DiSCmini reported faults and had to be cleaned several times. The DiSCmini impactor collected dust quite quickly and needed frequent cleaning (once per day). The AQ Indoor sensors were not cleaned during the entire measurement period, and they did not report faults. These sensors have a rather large cyclone at the entrance of the instrument, which seems to have helped keep the insides clean.

\section{DISCUSSION}

We successfully measured the LDSA distribution of several locations in the underground mine. In most locations, the majority of the total LDSA concentration was contributed by sub $300 \mathrm{~nm}$ particles; however, a significant portion (34\%-70\%) of LDSA was in larger particle sizes.

Despite the large size range of particles in the mine, electrical sensors were able to measure total LDSA with a good correlation to ELPI+ $\left(R^{2}=0.53-0.59\right)$. Somewhat surprisingly, discrepancies between sensors and ELPI+ measurements in the sensor comparison were unrelated to the presence of large particles, and perhaps slightly effected by sub $30 \mathrm{~nm}$ particles. The relationship was investigated by plotting the percentage difference of each sensor vs. ELPI+ on the y-axis, and the portion of particles over $300 \mathrm{~nm}$ on the x-axis (Fig. S3(a)), and similarly for particles smaller than $30 \mathrm{~nm}$ (Fig. S3(b)). A slight correlation was observed only in the latter case. A previous laboratory study showed that sub $20 \mathrm{~nm}$ particles are overestimated by LDSA sensors, while particles over $400 \mathrm{~nm}$ are underestimated (Todea et al., 2015), which is also explained by the relationship of the diffusion charger $P n$-curve (particle penetration efficiency multiplied by the number of unit charges) compared to the deposition probability function (Fierz et al., 2014). We did find some evidence of LDSA from large particles being underestimated by the AQ Indoor sensor from a measurement at the crushing station (Fig. S4, not included in the main measurements covered in this article). The main problem, however, was overloading of the sensors caused by coarse dust-an inlet cyclone removing coarse particles is a necessity for long-term measurement. An optical particle sensor would be a useful addition for locations with coarse particles, as they are better suited for particle diameters over $300 \mathrm{~nm}$.

Another recent study (Barrett et al., 2019) also examined particle sensors for underground mine applications; however, they focused on measuring the mass concentration of elemental or black carbon. They found good potential in a prototype black carbon sensor, which had good correlation with the reference method during field testing $\left(R^{2}=0.85\right)$. Barrett et al. (2019) used 30-minute averages for the comparison (compared to 5 minutes in our study -30 minute averaging would likely improve the correlation coefficient for the LDSA sensors). Particle loading was a problem in Barrett's study as well (Barrett et al., 2019).

Longer measurements with the two $A Q$ Indoor sensors indicated that particle populations in the mine mix and spread quickly, at least in these two locations (Fig. S1). This means that to improve air quality at a specific location requires changes in ventilation, in addition to controlling the location-specific sources. Based on total LDSA time series data, the air exchange rate at the dumping area was approximately $15(1 / \mathrm{h})$ (Fig. S7(a)) and $22(1 / \mathrm{h})$ in the crushing station (Fig. S7(b)).

Comparing the mean LDSA size distributions, the lowest concentrations in all sizes were seen in the maintenance area. Compared to the taconite mine study which also reported LDSA concentrations (Huynh et al., 2018), our results were in a similar range, although slightly higher (mean LDSA in our study: 79-405 $\mu \mathrm{m}^{2} \mathrm{~cm}^{-3}$, Huynh et al. (2018): 54-303 $\mu \mathrm{m}^{2} \mathrm{~cm}^{-3}$, excluding office and laboratory spaces, which were very clean, $<10 \mu \mathrm{m}^{2} \mathrm{~cm}^{-3}$ ). However, it should be noted that this previous study only included particles up to $1 \mu \mathrm{m}$ in diameter, which, if the distributions were similar to ours, leaves out $20 \%-30 \%$ of total LDSA. The LDSA values measured both in our study and in the previous taconite mine study are very high when comparing to the ambient background levels (e.g., $10-50 \mu \mathrm{m}^{2} \mathrm{~cm}^{-3}$ measured in Helsinki (Kuula et al., 2019)). Although the concentrations are high in comparison to ambient levels, they are comparable to several other working environments. For instance, personal exposure measurements by Setyawati et al. (2020) at a printing center revealed a maximum exposure of $220 \mu \mathrm{m}^{2} \mathrm{~cm}^{-3}$. The worker with highest exposure levels had an overall mean exposure of $106 \mu \mathrm{m}^{2} \mathrm{~cm}^{-3}$. In another exposure study, airport taxiway personnel were found to operate in mean LDSA concentrations of 59 to $174 \mu \mathrm{m}^{2} \mathrm{~cm}^{-3}$ (Marcias et al., 2019). 
Our study was not a personal exposure study and cannot be directly compared to these values; however, the potential for similar or even higher exposure exists.

The previous paper covering other measurements from this same campaign shows average $\mathrm{PM}_{10}$ was highest at the blasting area $\left(355 \mu \mathrm{g} \mathrm{m}^{-3}\right)$ and lowest in the maintenance area $\left(49 \mu \mathrm{g} \mathrm{m}^{-3}\right)$ (Saarikoski et al., 2019). While the LDSA is also higher in the blasting area than in the maintenance area, the average LDSA to mass ratios for these locations are 0.9 and 1.6 (units $\mu \mathrm{m}^{2} \mathrm{~cm}^{-3} \mu \mathrm{g}^{-1} \mathrm{~m}^{3}$ ), respectively. This indicates that one unit of particle mass in the blasting area is likely to be less toxic than one unit of mass in the maintenance area, based on the lung-deposition. Basing guidelines or regulation purely on mass concentration misses this effect.

\section{CONCLUSION}

This study shows that there are large variations in the LDSA concentrations and LDSA size distributions of an underground mine. This should be considered in future air quality guidelines and monitoring in occupational surroundings, which are currently trailing behind the science of aerosol health effects. Furthermore, this study shows that diffusion charging based particle sensors are a viable method for long-term monitoring of LDSA in underground mines if dust accumulation is taken care of, perhaps aided by optical sensors or other solutions for a larger particle size range coverage. Finally, occupational exposure limits need to be extended to smaller particles, and LDSA is a good choice for the measurement metric, as it is easily measurable and intrinsically health relevant.

\section{ACKNOWLEDGMENTS}

This work was supported by Academy of Finland (PARMAT, Grant No. 297804) and CONICYT, Chile. The help of the Kemi Mine staff during the measurement campaigns is highly appreciated. We would also like to thank Matthew Bloss and Jorge Vidal for their involvement in the measurement campaign and Dr. Antti Rostedt and Dr. Sampo Saari for preliminary campaign design. Pegasor provided two sensors for this study.

\section{SUPPLEMENTARY MATERIAL}

Supplementary material for this article can be found in the online version at https://doi.org/ 10.4209/aaqr.200660

\section{REFERENCES}

Afshar-Mohajer, N., Foos, R., Volckens, J., Ramachandran, G. (2020). Variability of aerosol mass and number concentrations during taconite mining operations. J. Occup. Environ. Hyg. 17, 114. https://doi.org/10.1080/15459624.2019.1688823

Barrett, C., Sarver, E., Cauda, E., Noll, J., Vanderslice, S., Volkwein, J. (2019). Comparison of several DPM field monitors for use in underground mining applications. Aerosol Air Qual. Res. 19, 2367-2380. https://doi.org/10.4209/aaqr.2019.06.0319

Braakhuis, H.M., Park, M.V.D.Z., Gosens, I., De Jong, W.H., Cassee, F.R. (2014). Physicochemical characteristics of nanomaterials that affect pulmonary inflammation. Part. Fibre Toxicol. 11, 18. https://doi.org/10.1186/1743-8977-11-18

Burnett, R., Chen, H., Szyszkowicz, M., Fann, N., Hubbell, B., Pope, C.A. 3rd, Apte, J.S., Brauer, M., Cohen, A., Weichenthal, S., Coggins, J., Di, Q., Brunekreef, B., Frostad, J., Lim, S.S., Kan, H., Walker, K.D., Thurston, G.D., Hayes, R.B., Lim, C.C., et al. (2018). Global estimates of mortality associated with longterm exposure to outdoor fine particulate matter. Proc. Natl. Acad. Sci. U.S.A. 115, 9592-9597. https://doi.org/10.1073/pnas.1803222115

Chang, P., Xu, G. (2017). A review of the health effects and exposure-responsible relationship of diesel particulate matter for underground mines. Int. J. Min. Sci. Technol. 27, 831-838. https://doi.org/10.1016/j.ijmst.2017.07.020 
Cheristanidis, S., Grivas, G., Chaloulakou, A. (2020). Determination of total and lung-deposited particle surface area concentrations, in central Athens, Greece. Environ. Monit. Assess. 192, 627. https://doi.org/10.1007/s10661-020-08569-8

Fierz, M., Meier, D., Steigmeier, P., Burtscher, H. (2014). Aerosol Measurement by Induced Currents. Aerosol Sci. Technol. 48, 350-357. https://doi.org/10.1080/02786826.2013.875981

Fissan, H., Neumann, S., Trampe, A., Pui, D.Y.H., Shin, W.G. (2007). Rationale and principle of an instrument measuring lung deposited nanoparticle surface area. J. Nanoparticle Res. 9, 53-59. https://doi.org/10.1007/s11051-006-9156-8

Goulaouic, S., Foucaud, L., Bennasroune, A., Laval-Gilly, P., Falla, J. (2008). Effect of polycyclic aromatic hydrocarbons and carbon black particles on pro-inflammatory cytokine secretion: Impact of PAH coating onto particles. J. Immunotoxicol. 5, 337-345. https://doi.org/10.1080/1 5476910802371016

Grahame, T.J., Klemm, R., Schlesinger, R.B. (2014). Public health and components of particulate matter: The changing assessment of black carbon. J. Air Waste Manage. Assoc. 64, 620-660. https://doi.org/10.1080/10962247.2014.912692

Huynh, T., Ramachandran, G., Quick, H., Hwang, J., Raynor, P.C., Alexander, B.H., Mandel, J.H. (2018). Ambient fine aerosol concentrations in multiple metrics in taconite mining operations. Ann. Work Exposures Health 63, 77-90. https://doi.org/10.1093/annweh/wxy086

Hyytinen, E.R., Tiina, S., Vainiotalo, S., Rantonen, J., Linnainmaa, M. (2016). Justification memo for inhalable and respirable dust target level. Text in Finnish. Finnish Institute of Occupational Health.

Järvinen, A., Aitomaa, M., Rostedt, A., Keskinen, J., Yli-Ojanperä, J. (2014). Calibration of the new electrical low pressure impactor (ELPI+). J. Aerosol Sci. 69, 150-159. https://doi.org/10.1016/ j.jaerosci.2013.12.006

Karjalainen, P., Rönkkö, T., Simonen, P., Ntziachristos, L., Juuti, P., Timonen, H., Teinilä, K., Saarikoski, S., Saveljeff, H., Lauren, M., Happonen, M., Matilainen, P., Maunula, T., Nuottimäki, J., Keskinen, J. (2019). Strategies to diminish the emissions of particles and secondary aerosol formation from diesel engines. Environ. Sci. Technol. 53, 10408-10416. https://doi.org/10.102 1/acs.est.9b04073

Keskinen, J., Pietarinen, K., Lehtimäki, M. (1992). Electrical low pressure impactor. J. Aerosol Sci. 23, 353-360. https://doi.org/10.1016/0021-8502(92)90004-F

Küpper, M., Asbach, C., Schneiderwind, U., Finger, H., Spiegelhoff, D., Schumacher, S. (2019). Testing of an indoor air cleaner for particulate pollutants under realistic conditions in an office room. Aerosol Air Qual. Res. 19, 1655-1665. https://doi.org/10.4209/aaqr.2019.01.0029

Kuula, J., Kuuluvainen, H., Rönkkö, T., Niemi, J. V., Saukko, E., Portin, H., Aurela, M., Saarikoski, S., Rostedt, A., Hillamo, R., Timonen, H. (2019). Applicability of optical and diffusion chargingbased particulate matter sensors to urban air quality measurements. Aerosol Air Qual. Res. 19, 1024-1039. https://doi.org/10.4209/aaqr.2018.04.0143

Kuula, J., Kuuluvainen, H., Niemi, J.V., Saukko, E., Portin, H., Kousa, A., Aurela, M., Rönkkö, T., Timonen, H. (2020). Long-term sensor measurements of lung deposited surface area of particulate matter emitted from local vehicular and residential wood combustion sources. Aerosol Sci. Technol. 54, 190-202. https://doi.org/10.1080/02786826.2019.1668909

Kuuluvainen, H., Rönkkö, T., Järvinen, A., Saari, S., Karjalainen, P., Lähde, T., Pirjola, L., Niemi, J. V., Hillamo, R., Keskinen, J. (2016). Lung deposited surface area size distributions of particulate matter in different urban areas. Atmos. Environ. 136, 105-113. https://doi.org/10.1016/j.atm osenv.2016.04.019

Kuuluvainen, H., Poikkimäki, M., Järvinen, A., Kuula, J., Irjala, M., Dal Maso, M., Keskinen, J., Timonen, H., Niemi, J. V., Rönkkö, T. (2018). Vertical profiles of lung deposited surface area concentration of particulate matter measured with a drone in a street canyon. Environ. Pollut. 241, 96-105. https://doi.org/10.1016/j.envpol.2018.04.100

Leavey, A., Reed, N., Patel, S., Bradley, K., Kulkarni, P., Biswas, P. (2017). Comparing on-road realtime simultaneous in-cabin and outdoor particulate and gaseous concentrations for a range of ventilation scenarios. Atmos. Environ. 166, 130-141. https://doi.org/10.1016/j.atmosenv.201 7.07.016

Lelieveld, J., Evans, J.S., Fnais, M., Giannadaki, D., Pozzer, A. (2015). The contribution of outdoor air pollution sources to premature mortality on a global scale. Nature 525, 367-371. https://doi.org/10.1038/nature15371 
Lepistö, T., Kuuluvainen, H., Juuti, P., Järvinen, A., Arffman, A., Rönkkö, T. (2020). Measurement of the human respiratory tract deposited surface area of particles with an electrical low pressure impactor. Aerosol Sci. Technol. 54, 958-971. https://doi.org/10.1080/02786826.202 0.1745141

Marcias, G., Casula, M., Uras, M., Falqui, A., Miozzi, E., Sogne, E., Pili, S., Pilia, I., Fabbri, D., Meloni, F., Pau, M., Sanna, A., Fostinelli, J., Massacci, G., d’Aloja, E., Filon, F., Campagna, M., Lecca, L. (2019). Occupational fine/ultrafine particles and noise exposure in aircraft personnel operating in airport taxiway. Environments 6, 35. https://doi.org/10.3390/environments6030035

Noll, J.D., Bugarski, A.D., Patts, L.D., Mischler, S.E., McWilliams, L. (2007). Relationship between elemental carbon, total carbon, and diesel particulate matter in several underground metal/ non-metal mines. Environ. Sci. Technol. 41, 710-716. https://doi.org/10.1021/es061556a

Oberdörster, G. (2001). Pulmonary effects of inhaled ultrafine particles. Int. Arch. Occup. Environ. Health 74, 1-8. https://doi.org/10.1007/s004200000185

Pirjola, L., Kuuluvainen, H., Timonen, H., Saarikoski, S., Teinilä, K., Salo, L., Datta, A., Simonen, P., Karjalainen, P., Kulmala, K., Rönkkö, T. (2019). Potential of renewable fuel to reduce diesel exhaust particle emissions. Appl. Energy 254, 113636. https://doi.org/10.1016/j.apenergy.201 9.113636

Pope, C.A. 3rd (2000). Epidemiology of fine particulate air pollution and human health: Biologic mechanisms and who's at risk? Environ. Health Perspect. 108, 713-723. https://doi.org/10.12 89/ehp.108-1637679

Pope, C.A. 3rd, Dockery, D.W. (2006). Health effects of fine particulate air pollution: Lines that connect. J. Air Waste Manage. Assoc. 56, 709-742. https://doi.org/10.1080/10473289.2006.1 0464485

Pronk, A., Coble, J., Stewart, P.A. (2009). Occupational exposure to diesel engine exhaust: A literature review. J. Exposure Sci. Environ. Epidemiol. 19, 443-457. https://doi.org/10.1038/je s.2009.21

Saarikoski, S., Salo, L., Bloss, M., Alanen, J., Teinilä, K., Reyes, F., Vázquez, Y., Keskinen, J., Oyola, P., Rönkkö, T., Timonen, H. (2019). Sources and characteristics of particulate matter at five locations in an underground mine. Aerosol Air Qual. Res. 19, 2613-2624. https://doi.org/10.42 09/aaqr.2019.03.0118

Setyawati, M.I., Singh, D., Krishnan, S.P.R., Huang, X., Wang, M., Jia, S., Goh, B.H.R., Ho, C.G., Yusoff, R., Kathawala, M.H., Poh, T.Y., Ali, N.A.B.M., Chotirmall, S.H., Aitken, R.J., Riediker, M., Christiani, D.C., Fang, M., Bello, D., Demokritou, P., Ng, K.W. (2020). Occupational inhalation exposures to nanoparticles at six singapore printing centers. Environ. Sci. Technol. 54, 23892400. https://doi.org/10.1021/acs.est.9b06984

Taxell, P., Hyytinen, E.-R., Ahonen, I., Santonen, T. (2015). Justification memo for diesel exhaust aerosol target level. Text in Finnish. Finnish Institute of Occupational Health.

Todea, A.M., Beckmann, S., Kaminski, H., Asbach, C. (2015). Accuracy of electrical aerosol sensors measuring lung deposited surface area concentrations. J. Aerosol Sci. 89, 96-109. https://doi.org/10.1016/j.jaerosci.2015.07.003

Tran, P.T.M., Ngoh, J.R., Balasubramanian, R. (2020). Assessment of the integrated personal exposure to particulate emissions in urban micro-environments: A pilot study. Aerosol Air Qual. Res. 20, 341-357. https://doi.org/10.4209/aaqr.2019.04.0201 